\title{
El suelo excluido del proceso urbanizador. Referencia a Castilla y León *
}

\author{
Tomás Quintana López \\ Catedrático de Derecho Administrativo \\ Universidad de León
}

Sumario: 1. HABILITACIÓN CONSTITUCIONAL PARA REGULAR LAS CLASES DE SUELO. 2. EL SUELO NO URBANIZABLE EN LA LEY 6/1998, DE 13 DE ABRIL, SOBRE RÉGIMEN DEL SUELO Y VALORACIONES. 3. EL SUELO NO URBANIZABLE EN CASTILLA Y LEÓN. A) Categorías de suelo rústico. B) La clasificación del suelo rústico. 4. LOS USOS DEL SUELO NO URBANIZABLE. 5. LOS USOS DEL SUELO RÚSTICO EN CASTILLA Y LEÓN. A) Régimen de autorizaciones de usos excepcionales en suelo rústico. B) Consideración de los usos del suelo rústico en los municipios sin planeamiento.

\section{HABILITACIÓN CONSTITUCIONAL PARA REGULAR LAS CLASES DE SUELO}

La regulación de las condiciones básicas que garanticen la igualdad de los españoles en el ejercicio de los derechos —en este caso el de propiedad-, a juicio del máximo intérprete de la Constitución, otorga al Estado legitimidad bastante para disponer la existencia de tres clases de suelo en todo el territorio nacional en función de su aptitud para fines urbanísticos. En efecto, mediante su Sentencia de 20 de marzo de 1997, el Tribunal Constitucional respaldó la adecuación a la Constitución de los artículos 3.2.c), 9.1 y otros del Texto Refundido aprobado por Real Decreto Legislativo 1/1992, de 26 de junio, sobre Régimen del Suelo y Ordenación Urbana, en cuanto definitorios de un estatuto básico regulador de los suelos urbano, urbanizable y no urbanizable, tríada de clases de suelo fijada por la legislación estatal que constitucionalmente es compatible con las precisiones normativas que para cada clase de suelo - las citadas u otras equivalentes- establezcan las Comunidades Autónomas en uso de sus competencias de ordenación territorial y urbanísticas.

Además de la cobertura que ofrece el artículo 149.1.1. ${ }^{\mathrm{a}}$ de la Constitución al Estado para que diseñe esa triple clasificación del suelo, otro precepto constitucional, el artículo 149.1.23. ${ }^{\mathrm{a}}$, al atribuir al Estado la compe-

* Este trabajo ha sido redactado como contribución al libro homenaje en honor al Prof. Dr. D. José María Boquera Oliver, con motivo de su jubilación. 
tencia exclusiva para establecer la legislación básica sobre la protección del medio ambiente, a juicio del Tribunal Constitucional, le habilita «para hacer posible - a través del planeamiento que corresponda a la Administración competente- la declaración de áreas de especial protección y las prohibiciones generales de usos incompatibles con aquéllas» ${ }^{1}$.

En consecuencia, si la previsión estatal de tres clases de suelo encuen-

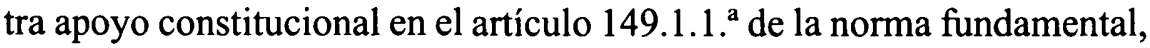
en cuanto se reconoce a esa clasificación como una expresión de la regulación de las condiciones básicas que incumbe realizar al Estado en aras de la igualdad de los españoles, la previsión de áreas de especial protección dentro del suelo no urbanizable por parte de la legislación del Estado tiene no solamente el apoyo del citado artículo constitucional, sino también el del artículo 149.1.23. ${ }^{\mathrm{a}}$, también de la norma fundamental ${ }^{2}$.

\section{EL SUELO NO URBANIZABLE EN LA LEY 6/1998, DE 13 DE ABRIL, SOBRE RÉGIMEN DEL SUELO Y VALORACIÓN}

Asegurado, por la STC 61/1997, de 20 de marzo, un espacio normativo al Estado para fijar los estatutos básicos de la propiedad del suelo con referencia a las tres clases citadas, la Ley 6/1998, de 13 de abril, fiel a los antecedentes de nuestro ordenamiento jurídico, ha previsto también tres clases de suelo: el urbano, el urbanizable y el no urbanizable -o clases equivalentes como concesión a las competencias normativas autonómicas- (art. 7).

La fidelidad a la tradición, sin embargo, no ha sido total, pues el legislador estatal de 1998 ha introducido una novedad de bulto en la definición normativa de las clases de suelo. En efecto, frente a los precedentes, como expresamente manifiesta la Exposición de Motivos de la Ley 6/1998: « (...) la presente Ley pretende facilitar el aumento de la oferta de

\footnotetext{
1 STC 61/1997, de 20 de marzo.

${ }^{2}$ Con referencia al artículo 17 del Decreto legislativo 1/1992, de 26 de junio, cuyo tenor era el siguiente: «El planeamiento territorial y urbanistico podrá delimitar áreas de especial protección en las que estará prohibida cualquier utilización que implique transformación de su destino o naturale$\mathrm{za}$, lesione el valor específico que se quiera proteger o infrinja el concreto régimen limitativo establecido por aquél», el Tribunal Constitucional, en su Sentencia de 20 de marzo de 1997, después de reconocer la cobertura que le otorga el artículo 149.1.23. ${ }^{2}$ de la Constitución, razonó como sigue: «De otro lado, el precepto impugnado guarda también relación con las condiciones básicas de ejercicio de la propiedad del suelo en la medida en que fija un límite general consistente en prohibir todo ejercicio del derecho contrario a lo que el área pretende precisamente preservan), razonamiento que avala el ejercicio de una competencia normativa ex artículo 149.1.1. ${ }^{\text {a }}$ de la Constitución, por parte del Estado.
} 
suelo, haciendo posible que todo el suelo que todavía no ha sido incorporado al proceso urbano, en el que no concurran razones para su preservación, pueda considerarse como susceptible de ser urbanizado»; es decir, dejando de lado al suelo urbano ${ }^{3}$, el suelo no urbanizable ya no es una clase residual de suelo delimitada a partir de la fijación de los límites del suelo urbanizable, sino que éste, ahora propiamente con carácter residual, es el suelo que no ha sido clasificado expresamente como no urbanizable por no incorporar valores susceptibles de protección.

A este nuevo principio respondía el Proyecto de Ley sobre Régimen del Suelo y Valoraciones, y a este principio responden las previsiones que sobre la clasificación del suelo contiene la vigente Ley 6/1998, de 13 de abril, sobre Régimen del Suelo y Valoraciones, si bien a su paso por las Cámaras Legislativas ha incorporado importantes añadidos. No obstante, debe advertirse desde ahora que la ecuación que surge de ese principio se invierte en los municipios sin planeamiento, pues en ellos, atendiendo a lo dispuesto en el artículo 11 de la Ley estatal que venimos considerando, el suelo del municipio será urbano cuando reúna las características que para esta clase de suelo exige el artículo 8 de la misma Ley, o bien, residualmente, será suelo no urbanizable.

Se deduce, pues, que sólo los municipios dotados de planeamiento general pueden disponer de las tres clases de suelo, y en ellos el suelo urbanizable vendrá determinado por los límites fijados para el suelo urbano y el suelo no urbanizable, tal como expresamente establece el artículo 10 de la Ley 6/1998. Ajena a nuestros objetivos la consideración de las características previstas para la clasificación del suelo como urbano y los márgenes en que se debe mover la Administración para la traslación de los criterios legales (art. 8) al territorio mediante la aprobación del correspondiente instrumento de planeamiento ${ }^{4}$, nuestra primera apreciación en

\footnotetext{
${ }^{3}$ Con los límites derivados de la doctrina del Tribunal Constitucional mantenida en su Sentencia de 20 de marzo de 1997, y evitando por tanto interferir en las competencias normativas de las Comunidades Autónomas en matería urbanística, el artículo 8 de la Ley 6/1998, de 13 de abril, sin consideración alguna hacia los instrumentos de planeamiento llamados a clasificar el suelo como urbano, determina las condiciones de éste para que según la normativa aplicable en cada Comunidad Autónoma sea delimitada su extensión territorial, operación que la jurisprudencia considera como una actuación administrativa reglada, por contraposición a la determinación de las otras clases de suelo operadas con base en el Decreto Legislativo 1/1992, de 26 de junio, o normativa anterior; en este sentido, vid. las recientes Sentencias del Tribunal Supremo de 17 de junio de 1997 (Ar. 5.356), 18 de junio de 1998 (Ar. 4.558) y 16 de diciembre de 1998 (Ar. 10.106); en todo caso, para conocer matizadamente la jurisprudencia y las posiciones doctrinales al respecto, vid. E. Desdentado Daroca, Discrecionalidad administrativa y planeamiento urbanistico. Construcción teórica y análisis jurisprudencial, Aranzadi, 1997, pp. 405 y ss.
}

${ }^{4}$ Una breve referencia en la nota al pie de la página anterior. 
relación con la nueva configuración legal del suelo no urbanizable es que, consecuentemente con el afirmado abandono de su delimitación residual, ahora, con la aprobación de la Ley 6/1998, el suelo no urbanizable ha pasado a ser definido positivamente por el legislador.

En efecto, el artículo 9 de esta Ley fija una serie de reglas determinantes para la clasificación del suelo no urbanizable: el previo sometimiento de los terrenos a alguno de los múltiples regímenes de especial protección previstos en las legislaciones estatal o autonómicas - de cita casi interminable - que impidan su transformación debido a los valores paisajísticos, históricos, arqueológicos, científicos, ambientales o culturales, por una parte, o bien por los riesgos que supondría su transformación para propiciar usos distintos a los propios del suelo no urbanizable que se vinieran realizando. La redacción que contiene el artículo 9, en su regla primera, permite afirmar que la clasificación de los terrenos a que me acabo de referir como suelo no urbanizable precisa únicamente la constatación de que están sometidos a un régimen de especial protección para la tutela de los valores indicados o para evitar riesgos naturales, régimen de especial protección que ya le es dado a la Administración encargada de clasificar el suelo y que se impone a su capacidad de decidir.

Similares efectos para la Administración responsable de efectuar la clasificación del suelo produce el inciso final de la misma regla primera del artículo 9, en cuanto también impone la inclusión en la clase de suelo no urbanizable de aquellos terrenos sujetos a limitaciones o servidumbres para la protección del dominio público, remisión que lo es a las diversas regulaciones del demanio, que, por tanto, determinan la extensión del suelo no urbanizable a las zonas colindantes con el mismo mediante una operación para el responsable del planeamiento estrictamente reglada, y de carácter más material que jurídico.

Frente a la total ausencia de capacidad decisoria de la Administración en la clasificación del suelo no urbanizable, que necesariamente ha de deducirse de la regla primera del artículo 9 hasta ahora considerada, la segunda regla contiene otras dos previsiones dirigidas a las Administraciones responsables de redactar y aprobar el instrumento de planeamiento encargado de la clasificación del suelo, en las que, con menor o mayor intensidad, se traslada a la Administración la decisión de clasificar o no determinados terrenos como suelo no urbanizable.

Efectivamente, con una redacción poco afortunada la regla segunda del artículo 9 remite a la Administración la apreciación de los valores paisajísticos, históricos, arqueológicos, científicos, ambientales o culturales 
del terreno para preservar los tradicionales destinos - agrícola, forestal o ganadero- o sus riquezas naturales mediante su clasificación como suelo no urbanizable. Esta previsión, al igual que, al menos parcialmente, las contenidas en la regla anterior de este artículo 9 de la Ley 6/1998, vincula la clasificación del suelo como no urbanizable con la preservación de valores ambientales o culturales, si bien en un caso esa decisión tuitiva se adopta a través de los instrumentos de planeamiento territorial o de carácter sectorial y en esos términos se integra en el planeamiento urbanístico; en el otro caso, de acuerdo con la segunda regla, por el contrario, la decisión la toma la Administración responsable al elaborar y aprobar el instrumento de planeamiento a través del que se fija la clasificación del suelo.

Constatado, pues, que la regla segunda del artículo 9 de la Ley 6/1998, de 13 de abril, que ahora nos ocupa, remite a la Administración que, según la legislación autonómica, elabora y aprueba el planeamiento general, corresponde ahora considerar el margen decisorio de que aquélla dispone, pues, como ya se ha señalado, la clasificación del suelo no urbanizable, en este caso, debe obedecer a la necesidad de preservar valores paisajísticos, arqueológicos, científicos, ambientales, culturales, textualmente relacionados - aunque de manera poco afortunada - con el valor agrícola, forestal, ganadero o con las riquezas naturales que guarden los terrenos.

Pues bien, a mi juicio, el objetivo protector que está en la base de esta previsión determinante de la clasificación del suelo como no urbanizable es muy similar a la que contenía el artículo 80.b) del Texto Refundido de la Ley sobre Régimen del Suelo y Ordenación Urbana, aprobado por Real Decreto 1346/1976, de 9 de abril ${ }^{5}$, por lo que parece razonable traer a colación ahora las pautas conforme a las que se viene interpretando este precepto. En esta línea, lo primero que cabe advertir es que en la legislación urbanística anterior a la Ley 6/1998, de 13 de abril, dentro de la consideración residual que tenía el suelo no urbanizable, el especialmente protegido tenía una consideración positiva, en cuanto que se exigía la constatación administrativa de que los terrenos estaban dotados de los caracteres inherentes a los valores susceptibles de protección ${ }^{6}$, lo que, evidente-

\footnotetext{
5 «Constituirán el suelo no urbanizable: b) Los espacios que el plan determine para otorgarles una especial protección, a los efectos de esta Ley, en razón de su excepcional valor agrícola, forestal o ganadero, de las posibilidades de explotación de sus recursos naturales, de sus valores paisajísticos, históricos o culturales o para la defensa de la fauna, la flora o el equilibrio ecológico.»

${ }^{6}$ A veces esa constatación se ha identificado judicialmente con «el mero reconocimiento de su singularidad con el fin de proteger adecuadamente los espacios naturales del municipio» mediante la
} 
mente, necesitaba de una decisión administrativa en forma de determinación del correspondiente instrumento de planeamiento, decisión estrechamente vinculada a los valores a cuya protección se ordenaba la previsión legislativa, lo que convertía, en todo caso, a aquélla en una decisión reglada y, por tanto, susceptible de control judicial ${ }^{7}$, capaz de anular una clasificación de terrenos como suelo no urbanizable de especial protección cuando aquéllos carecieran de los caracteres exigidos para su tutela ${ }^{8}$, o bien no fueran razonadamente puestos de manifiesto en la memoria del instrumento de planeamiento de clasificación del suelo ${ }^{9}$.

A mi juicio, todas estas pautas interpretativas sobre el artículo 80.b) del Texto Refundido en materia urbanística de 1976 son más que aprovechables para guiar la aplicación de la previsión sobre la clasificación de suelo como no urbanizable que contiene la regla segunda del artículo 9 de la vigente Ley 6/1998, ahora considerada, en cuanto que en ambos preceptos se procede a la clasificación - de suelo no urbanizable de especial protección, en el primer caso, y de suelo no urbanizable, en el segundoatendiendo a la preservación de valores históricos, arqueológicos, culturales, paisajísticos.... o inherentes a los usos primarios del suelo, por lo que las determinaciones del planeamiento clasificando el suelo como no urbanizable una vez en vigor la Ley 6/1998, de 13 de abril, ha de ser entendida como una decisión necesariamente dotada de un fundamento razonable, capaz de evidenciar la existencia en el suelo susceptible de esa clasificación de alguno o algunos de los valores que el legislador ha ordenado preservar mediante la incorporación de la regla segunda en el artículo 9 de la Ley que se acaba de citar.

El margen de apreciación de la Administración para la clasificación del suelo no urbanizable en atención a los criterios hasta ahora tenidos en cuenta resulta ciertamente limitado, según se deduce del análisis efectua-

correspondiente determinación del Plan General de Ordenación Urbana (STS de 22 de diciembre de 1997, Ar. 9.617), aunque los Tribunales suelen dejar un margen de apreciación y, consecuentemente, de decisión a la Administración responsable de la formulación y aprobación del planeamiento, como resulta de la STS de 6 de mayo de 1998 (Ar. 3.617), al considerar como susceptible de protección un espacio ocupado por una cantera en el interior de una masa forestal de miles de hectáreas, porque lo contrario «carece de toda lógica urbanística».

7 Vid. E. Desdentado Daroca, Discrecionalidad..., cit., pp. 417 a 420.

8 STS de 17 de junio de 1997, Ar. 5.460: «(...) la mera proximidad a zonas de especial interés no es motivo para que el suelo sea clasificado como no apto para urbanizar y de especial protección, pues en algún punto habrá de señalarse el límite entre uno y otro tipo de suelo».

9 Lo que se deduce contrario sensu de las Sentencias del Tribunal Supremo de 28 de septiembre de 1998, Ar. 6.948, y 29 de septiembre de 1998, Ar. 7.982. 
do. Pero, además, el artículo 9.2. ${ }^{a}$ in fine de la Ley 6/1998, de 13 de abril, contiene una previsión que remite al planeamiento general la clasificación como suelo no urbanizable de aquellos terrenos «que considere inadecuados para un desarrollo urbano», previsión que, sin duda, contrariamente a lo anterior, otorga al responsable de elaborar y aprobar el planeamiento una considerable capacidad decisoria ${ }^{10}$.

No obstante, sin perjuicio de ulteriores precisiones sobre la normativa autonómica y, en particular, sobre la legislación urbanística de Castilla y León, puede mantenerse que la discrecionalidad que ha venido reconociendo la jurisprudencia a la Administración encargada de redactar y aprobar el planeamiento para la clasificación del suelo urbanizable y no urbanizable en la aplicación del Texto Refundido en materia urbanística de $1976^{11}$, se ha reducido notablemente después de la aprobación de la Ley $6 / 1998$, de 13 de abril, pues incluso de su artículo 9.2. ${ }^{\mathrm{a}}$ in fine, últimamente considerado, sólo es posible deducir una discrecionalidad muy matizada, cercana al concepto jurídico indeterminado, fruto más bien de la falta de precisión normativa atribuible a la legislación estatal a causa de los límites competenciales en que se mueve el Estado cuando de materia urbanística se trata; imprecisión, por tanto, susceptible de ser reparada en sede autonómica mediante la prescripción de circunstancias que determinen la preservación de terrenos del proceso urbanizador, prescripción que conduce a su clasificación como suelo no urbanizable por «inadecuado» para ser urbanizado.

Con todo, sin contar ahora con las precisiones que la legislación urbanística autonómica pueda allegar para completar el significado de terrenos «inadecuados para un desarrollo urbano» (art. 9.2. in fine de la Ley 6/1998, de 13 de abril), parece oportuno dedicar alguna atención a esta prescripción con objeto de pautar su aplicación o, en su caso, su desarrollo normativo en sede autonómica.

Pues bien, para cumplir este objetivo resulta de interés partir de la aceptada, pero matizable, discrecionalidad administrativa que para la clasificación del suelo urbanizable y no urbanizable común resultaba de la aplicación de las previsiones que contenía sobre la clasificación del suelo el Texto Refundido en materia urbanística de 1976, discrecionalidad compatible con el control jurisdiccional, que, como razona E. DESDENTA-

${ }^{10}$ Cfr. T. R. Fernández Rodriguez, Manual de Derecho Urbanistico, 13. a edición, Abella, Madrid, 1998, p. 132.

11 Son muy abundantes los pronunciamientos jurisprudenciales en este sentido; recientemente, Sentencias del Tribunal Supremo de 17 de junio de 1997 (Ar. 5.356) y de 18 de junio de 1998 (Ar. 4.558). 
DO DAROCA después de estudiar opiniones doctrinales y los pronunciamientos jurisdiccionales sobre el particular, se puede proyectar sobre la memoria del correspondiente instrumento de planeamiento y sobre la racionalidad de datos y argumentos sobre los que se basan las determinaciones de clasificación del suelo urbanizable y no urbanizable común ${ }^{12}$. La clasificación del suelo urbanizable y no urbanizable común no obedecía, pues, en el Texto Refundido de 1976 al manejo de una potestad administrativa discrecional ajena al control jurisdiccional, control que se proyecta a través de la constatación de los hechos determinantes y de su congruente inserción en los juicios prospectivos que contenga la memoria, así como mediante el contraste del ejercicio de la potestad de planeamiento con los principios generales del Derecho, que «informan todo el ordenamiento jurídico y por tanto también la norma habilitante que atribuye la potestad discrecional, lo que exige que la actuación de ésta haya de ajustarse a la exigencia de dichos principios generales del Derecho....» ${ }^{13}$. Siendo esto así, es decir, constatado que aunque tradicionalmente el legislador no haya pautado expresamente las decisiones del planeamiento determinantes de la clasificación del suelo en urbanizable y no urbanizable común, viene siendo ajustado la reducción de la discrecionalidad mediante el control de los resultados de su ejercicio, lo que, consecuentemente, limita el margen de decisión de la Administración responsable de la elaboración y aprobación del planeamiento, lo cual, a mi juicio, determina que la capacidad de apreciación de la Administración sea más reducida y, por tanto, las posibilidades judiciales de control sean más intensas, cuando, conforme al último inciso del artículo 9.2. ${ }^{\mathrm{a}}$ de la Ley 6/1998, de 13 de abril, han de ser clasificados como suelo no urbanizable aquellos terrenos «inadecuados para un desarrollo urbano», criterio interpretativo al que además prestan sustento los siguientes argumentos: la citada Ley estatal sobre Régimen del Suelo y Valoraciones, según manifiesta su preámbulo, «pretende facilitar el aumento de la oferta de suelo, haciendo posible que todo el suelo que todavía no ha sido incorporado al proceso urbano, en el que no concurran razones para su preservación, pueda considerarse como susceptible de ser urbanizado. Y ello de acuerdo con el planeamiento y la legislación territorial o sectorial, en razón de sus valores ambientales (...) o de su justificada inadecuación para el desarrollo urbano», por lo que cualquier determinación del planeamiento clasificatoria del suelo no urbanizable ha de fundamentarse o bien en razones tuitivas, en atención a la preservación de los valores a que hace referencia el artículo 9 de la Ley 6/1998, a cuya interpretación se ha atendido

12 E. Desdentado Daroca, Discrecionalidad..., cit., pp. 413 y ss.

13 Sentencia del Tribunal Supremo de 24 de julio de 1987 (Ar. 7.671). 
en páginas precedentes, o bien en que los terrenos que se clasifiquen en no urbanizables resulten inadecuados para el desarrollo urbano, lo que también habrá de justificarse debidamente en la memoria del correspondiente instrumento de planeamiento, no tanto con apoyo en que el terreno en cuestión no es necesario para el previsible desarrollo urbanístico de la población ${ }^{14}$, sino en que este destino no es adecuado, lo que en gran medida debe obedecer a la propia realidad de los terrenos y su ubicación; de lo contrario, es decir, a falta de justificación o justificación no razonable, la clasificación de los terrenos como suelo no urbanizable, con apoyo en su falta de adecuación para soportar el desarrollo urbano, incurrirá en arbitrariedad, pues si no es razonablemente inadecuado para ser clasificado -residualmente - como urbanizable, su inclusión en el suelo no urbanizable privaría de expectativas urbanísticas a sus propietarios, con flagrante infracción del principio de igualdad en relación con los propietarios de suelo clasificado como urbanizable. En definitiva, partiendo de los nuevos principios conforme a los que el legislador estatal de 1998 ha diseñado la clasificación del suelo $\mathrm{y}$, en particular, dado el carácter residual que ha otorgado al suelo urbanizable, la clasificación del suelo como no urbanizable por razón de la inadecuación de los terrenos para acoger desarrollo urbanístico, debe considerarse como una prescripción que integra elementos reglados, por tanto, susceptibles de control judicial; esta apreciación, además, es compatible con la pormenorización o desarrollo del criterio de la inadecuación del terreno para el desarrollo urbano por parte de los legisladores autonómicos, pues este criterio determinante de la clasificación del suelo como no urbanizable, desde el punto de vista del reparto de responsabilidades normativas con incidencia territorial entre el Estado y la Comunidades Autónomas, tiene carácter básico ${ }^{15}$.

\section{EL SUELO NO URBANIZABLE EN CASTILLA Y LEÓN}

Con la denominación de suelo rústico, el suelo que en Castilla y León se pretende preservar de los procesos de urbanización ha sido objeto de regulación en la Ley 5/1999, de 8 de abril, de Urbanismo de Castilla y León, cuyo artículo 15 prácticamente reproduce las previsiones de la Ley estatal 6/1998, de 13 de abril, que ya conocemos. En efecto, tendrán la condición de suelo rústico los terrenos que ya gozan de un régimen de especial protección, los que sin estar afectados por él, sin embargo, sean

14 Lo que, por el contrario, está en la base de la clasificación del suelo urbanizable de acuerdo con el Texto Refundido en materia urbanística de 1976; vid. E. García de Enterría y L. Parejo Alfonso, Lecciones de Derecho urbanistico, Civitas, Madrid, 1981, p. 263.

15 Disposición final única de la Ley 6/1998, de 13 de abril, sobre Régimen del Suelo y Valoraciones. 
portadores de valores que les hagan susceptibles de tutela, los terrenos amenazados por riesgos naturales o los inadecuados para su urbanización. No obstante, más allá de la mencionada reproducción, el citado artículo 15 de la Ley autonómica incorpora algunas previsiones novedosas determinantes de la clasificación de los terrenos como suelo rústico; así, por ejemplo: la inclusión de los usos educativos o recreativos; más importante aún, al disponer que «los terrenos que habiendo presentado dichos valores -ecológicos, ambientales, arqueológicos... - en el pasado, deban protegerse para facilitar su recuperación», se da un salto cualitativo en favor de los instrumentos de planeamiento encargados de clasificar los terrenos en las distintas clases de suelo, al quedar habilitados no sólo para incorporarlos al llamado suelo rústico para tutelar sus valores actuales, sino también para restablecer los valores perdidos, lo que constituye una importante previsión que responde a la obligación de restaurar el medio ambiente que impone a los poderes públicos el artículo 45.2 de la Constitución; los riesgos tecnológicos, con expresa cita de la contaminación, son añadidos a los riesgos naturales como circunstancia que exige también la clasificación de los terrenos como suelo rústico. Por último, con objeto de pautar la inclusión en esta clase de suelo de los terrenos inadecuados para su urbanización, el artículo 15.d) de la Ley de Urbanismo de Castilla y León traslada a la Administración la fijación por vía reglamentaria de los criterios conforme a los que haya de interpretarse la cláusula de inadecuación, pormenorización reglamentaria que, consecuentemente con lo razonado más atrás, debe enmarcarse dentro de los márgenes derivados del principio en que se inspira el legislador estatal de 1998 para integrar los terrenos en suelo urbanizable o no urbanizable; no obstante, como se advertirá a continuación, en la regulación de las distintas categorías de suelo rústico se incluyen criterios interpretativos de la inadecuación de los terrenos para ser clasificados como suelo urbanizable.

\section{A) Categorías de suelo rústico}

El deficiente comportamiento que tradicionalmente la legislación urbanística y los propios instrumentos de planeamiento han tenido con el suelo no urbanizable está siendo superado por las previsiones que en los últimos años vienen estableciendo las Comunidades Autónomas en uso de sus competencias en materia urbanística y de ordenación territorial ${ }^{16}$. Un buen ejemplo, que sirve para constatar lo señalado, lo encontramos en

\footnotetext{
16 Una amplia referencia en T. QUINTANA LOPEZ, «Tradición y renovación en el control urbanístico de los usos constructivos en suelo no urbanizable», Revista de Derecho Urbanistico y Medio Ambiente, $\mathrm{n} .{ }^{\circ} 158$, pp. 114 y ss.
} 
el artículo 16 de la Ley 5/1999, de 8 de abril, de Urbanismo de Castilla y León, al prever la posibilidad de que en el suelo rústico y, por tanto, ajeno a los procesos de urbanización, se puedan distinguir diversas categorías de suelo «según los valores que los caractericen», como textualmente señala la Exposición de Motivos de la Ley.

La primera categoría - suelo rústico común — tiene una delimitación residual, al estar integrada «por los terrenos que no se incluyan en ninguna de las otras categorías»; pues bien, a la vista de las otras categorías de suelo rústico, la común acogerá los terrenos que se incluyan en esta clase de suelo siempre que esta clasificación no determine su inclusión en alguna de las siguientes categorías previstas en ese mismo artículo 16.

El resto de categorías de suelo rústico son las siguientes: Suelo rústico de entorno urbano, cuya previsión responde a la preservación de los terrenos incluidos en esa categoría en función de «no comprometer su desarrollo futuro» (del núcleo de población), lo que equivale a posibilitar futuras alteraciones del planeamiento general, o «preservar el paisaje y las perspectivas tradicionales». Suelo rústico con asentamiento tradicional, con el fin de «preservar formas tradicionales de ocupación humana del territorio». Suelo rústico de protección agropecuaria, "por su interés, calidad $\mathrm{u}$ otras características agrícolas o ganaderas». Suelo rústico con protección de infraestructuras, es decir, los terrenos clasificados como suelo rústico y que deban ser objeto de especial protección por estar ocupados o estar destinados a ser ocupados por infraestructuras, o bien tengan la consideración de zonas de defensa de las mismas conforme a la legislación sectorial. Suelo rústico con protección cultural, constituido por bienes inmuebles que ya tienen un específico régimen de protección (Bienes de Interés Cultural, catalogados) o terrenos portadores de valores culturales. Suelo rústico de protección natural, integrado por terrenos que gozan de un estatuto específico de protección conforme a la legislación de espacios naturales protegidos, o bien por tratarse de espacios afectados por la normativa de aguas o portadores de valores actuales o susceptibles de ser recuperados. Por último, el suelo rústico con protección especial, que se preserva de los procesos urbanísticos por estar amenazado por riesgos naturales o tecnológicos o por «cualesquiera otras razones justificadas».

Como habrá podido deducirse de la relación de categorías de suelo rústico que prevé el artículo 16 de la Ley de Urbanismo de Castilla y León, se denota la voluntad de tutelar los valores que el legislador estatal y el propio legislador de Castilla y León sitúan como fundamento del suelo preservado de la urbanización; pero, además, es importante advertir 
que el propio artículo 16 que nos ocupa, al relacionar las distintas categorías de suelo rústico, precisa algunas circunstancias que en el territorio de Castilla y León deben considerarse determinantes de que los terrenos en que se presenten deban ser considerados inadecuados para ser urbaniza$\operatorname{dos}{ }^{17}$.

En todo caso, las determinaciones urbanísticas delimitadoras de las distintas categorías de suelo rústico son perfectamente controlables judicialmente dado que deben atender a criterios objetivos, en la misma línea de lo argumentado cuando nos referimos a los límites en que, conforme al Texto Refundido en materia urbanística de 1976, se ha debido mover la Administración para calificar, dentro del suelo no urbanizable, al especialmente protegido. En este marco, sin embargo, encaja con dificultad el inciso final del artículo 16.1.h) de la Ley de Urbanismo de Castilla y León, al abrir la posibilidad de ser incluidos en la categoría de suelo rústico de especial protección «los terrenos que el planeamiento estime necesario proteger por cualesquiera otras razones justificadas», razones que en aras de la seguridad jurídica y para conjurar posibles arbitrariedades, por vía reglamentaria se deberian precisar las circunstancias que permitan excluir del proceso de urbanización ciertos terrenos y, por ello, someterlos a un estatuto de protección especial.

La inclusión de los terrenos en una de las categorías de suelo rústico para aquellos casos - previsiblemente frecuentes - en que el terreno presente características que le hagan susceptible de ser calificado en dos o más de ellos, debe obedecer a una serie de reglas ${ }^{18}$; así, en efecto, el terreno podrá ser incluido en la categoría en que se proporcione mayor protección, $o$ bien en varias de las categorías previstas, aplicando de forma parcial y complementaria los regímenes de cada una de ellas; finalmente, como cláusula de cierre, en caso de contradicción en la aplicación de los distintos regímenes, se hará efectivo el que proporcione mayor protección.

\section{B) La clasificación del suelo rústico}

Fijadas las condiciones básicas determinantes de la clasificación del terreno como suelo no urbanizable por Ley 6/1998, de 13 de abril, del Estado, la legislación autonómica de Castilla y León, además de, según

\footnotetext{
17 Así, por ejemplo: «terrenos contiguos a los núcleos de población que el planeamiento estime necesario proteger para no comprometer su desarrollo futuro", «para preservar perspectivas tradicionales».

${ }^{18}$ Artículo 16.1.h) de la Ley 5/1999, de 8 de abril, de Urbanismo de Castilla y León.
} 
ha quedado anotado, proceder a un cierto desarroilo de aquéilas y a definir categorías dentro del que denomina suelo rústico, establece un sistema de clasificación, bien a través de instrumentos de planificación, o mediante la tradicional aplicación directa de las previsiones legales a falta de instrumento planificador.

La clasificación de terrenos del término municipal como suelo rústico es una de las determinaciones que pueden incorporar los dos instrumentos de planeamiento general que regula la Ley de Urbanismo de Castilla y León. En efecto, los artículos 41.b) y 44.1.a) de la citada Ley prevén, respectivamente, que el Plan General de Ordenación Urbana y las Normas Urbanísticas Municipales «establecerán» o «podrán limitarse a establecer» la «clasificación de todo el término municipal en todas o algunas de las clases y categorías de suelo definidas en los artículos 11 a 16 según las características del territorio».

Además de los instrumentos de planeamiento general ya considerados, la clasificación del suelo y, en particular, de los terrenos como suelo rústico, puede realizarse en Castilla y León a través de uno de los instrumentos de ordenación territorial previstos en la Ley 10/1998, de 5 de diciembre, de Ordenación del Territorio, denominado Directrices de Ordenación de Ámbito Subregional ${ }^{19}$, cuyo contenido incorpora como determinación potestativa las «normas urbanísticas subsidiarias que definan la ordenación urbanística en los municipios sin planes de ordenación propios, clasificando el suelo según lo dispuesto en la ordenación urbanística, estableciendo en los casos necesarios la normativa sobre uso del suelo, en especial en lo relativo a la urbanización y edificación en suelo urbano y a la protección del suelo rústico»» ${ }^{20}$. De la norma transcrita se deduce que, mediante las llamadas Directrices de Ordenación de Ámbito Subregional, es posible la clasificación del suelo en los municipios que carezcan de alguno de los instrumentos de planeamiento general habilitados para ello, según se ha señalado; pero, además, las citadas Directrices de Ordenación podrán establecer regímenes de protección en el suelo rústico, lo que equivale a decir, con la terminología de la posterior Ley de Urbanismo de Castilla y León, que las normas urbanísticas subsidiarias

19 El artículo 14.1 de la Ley 10/1998, de 5 de diciembre, de Ordenación del Territorio de la Comunidad de Castilla y León, dispone: «Las Directrices de Ordenación de Ámbito Subregional tendrán como objetivo la planificación de las áreas de la Comunidad que precisen una consideración conjunta y coordinada de sus problemas territoriales, en especial en lo relativo a sus recursos, infraestructuras y equipamientos.»

${ }^{20}$ Artículo 17.1.h) de la Ley 10/1998, de 5 de diciembre, de Ordenación del Territorio de la Comunidad de Castilla y León. 
que contengan las citadas directrices de ordenación podrán incorporar todas o algunas de las categorías de suelo rústico previstas en la normativa urbanística de la Comunidad ${ }^{21}$.

Por último, tal y como ya quedó anticipado, la consideración del terreno como suelo rústico, además mediante su clasificación a través del correspondiente instrumento de planificación, y a falta de éstos, obedece a las propias previsiones legales; las básicas del artículo 11 de la estatal Ley sobre Régimen del suelo y Valoraciones y las que contiene el artículo 30 de la Ley de Urbanismo de Castilla y León, precepto este último que distingue el suelo urbano del suelo rústico en los municipios sin planeamiento urbanístico en función de lo siguiente: «Tendrán la condición de suelo urbano los terrenos que formen parte de un núcleo de población y cuenten con acceso rodado, abastecimiento de agua, saneamiento y suministro de energía eléctrica, así como terrenos consolidados por la edificación en al menos la mitad de los espacios no ocupados por vías públicas o espacios libres existentes»; por el contrario, «tendrán la condición de suelo rústico los demás terrenos del término municipal».

Pues bien, al margen de la interpretación de las diversas reglas determinantes de la consideración del suelo como urbano, que el artículo 30.1 de la Ley de Urbanismo de Castilla y León reproduce a partir del contenido del artículo 8.a) de la Ley 6/1998 de 13 de abril, del Estado, incliyendo además la prescripción del núcleo de población y una más precisa indicación de lo que ha de considerarse como terrenos consolidados por la edificación, al margen, decía, de las posibilidades interpretativas que ofrecen estas prescripcior ${ }^{2}{ }^{22}$, la aplicación de las mismas para distinguir el suelo urbano del rústico en Castilla y León solamente opera en los municipios carentes de planeamiento general que tampoco estén afectados por la correspondiente determinación de clasificación del suelo que, como hemos visto, pueden contener las Directrices de Ordenación de Ámbito Subregional; en definitiva, dicho de otra forma, las prescripciones previstas en el artícu-

\footnotetext{
${ }^{21}$ No es éste el lugar para analizar ni siquiera con un mínimo detalle la trascendental importancia que tienen las normas urbanisticas subsidiarias que incorporen las Directrices de Ordenación de Ambito Subregional para la ordenación urbanística de los municipios que no dispongan de instrumentos de planeamiento general, lo cual, sin embargo, plantea algunas cuestiones: ¿es suficiente la intervención de los municipios en el procedimiento de aprobación de las Directrices de Ordenación de Ámbito Subregional para reflejar debidamente los intereses de aquéllos en la ordenación urbanística municipal que contengan las citadas directrices?; jes posible el desarrollo de las normas urbanísticas subsidiarias por los instrumentos de planeamiento de desarrollo previstos en la Ley de Urbanismo de Castilla y León?

22 Vid., sobre este particular, un interesante análisis jurisprudencial en E. DESDENTADO Daroca, Discrecionalidad..., cit., pp. 410 a 413.
} 
lo 30 de la Ley $5 / 1999$, de Urbanismo, de Castilla y León, son aplicables a los municipios que, carentes de planeamiento general y no afectados por ninguna determinación de ordenación territorial de clasificación del suelo, a su entrada en vigor tampoco dispongan de Proyectos de Delimitación de Suelo Urbano, mientras no se adapten a la citada Ley mediante la aprobación del correspondiente instrumento de planeamiento general o sean aprobadas las Directrices de Ordenación de Ámbito Subregional que contengan normas urbanísticas subsidiarias con previsiones de clasificación del suelo (Disposición Transitoria Primera y Cuarta).

\section{LOS USOS DEL SUELO NO URBANIZABLE}

Extremadamente respetuoso con las competencias normativas de las Comunidades Autónomas en la materia, el artículo 20 de la Ley 6/1998, de 13 de abril, sobre Régimen del Suelo y Valoraciones, diseña a grandes trazos el estatuto del derecho de propiedad sobre el suelo no urbanizable ${ }^{23}$, estableciendo como regla general que la propiedad de suelo clasificado como no urbanizable da derecho a «usar y disfrutar y disponer» conforme a la naturaleza de los terrenos, que expresamente se identifica con los destinos agrícola, forestal, ganadero, cinegético u otros vinculados a la utilización racional de los recursos naturales.

La amplitud de estos posibles destinos, no obstante, se halla delimitada tanto por las previsiones legales, urbanísticas o sectoriales - de origen estatal o autonómicas-, como por los instrumentos de ordenación territorial o urbanísticos que afecten a los terrenos clasificados o considerados como suelo no urbanizable.

Además de esta innominada remisión a las diversas normativas de incidencia territorial, el apartado segundo del mismo artículo 20 prohíbe las parcelaciones urbanísticas en el suelo no urbanizable cuando, a través de cualquiera de los actos jurídicos en que pueden materializarse, se vulneren las disposiciones que garantizan un mínimo de integridad dominical en el suelo ajeno a los procesos urbanísticos, previsión que nuevamente supone una remisión a las regulaciones en que se prevén los límites al ius disponiendi, para preservar unidades mínimas de terreno por razones de rentabilidad agraria u otras, unidades mínimas cuya extensión está en manos de las Comunidades Autónomas.

${ }^{23}$ Transitoriamente, antes de su inclusión en sectores o ámbitos para el desarrollo, los terrenos que tengan la consideración de urbanizables quedan sometidos al régimen de usos del suelo no urbanizable, según dispone el artículo 17 en su párrafo segundo, de la Ley 6/1998. 
Si antes se aludía a una regla general en relación con los usos de que es susceptible el suelo no urbanizable, es porque el propio artículo 20 que ahora nos ocupa incorpora una excepción a la regla general analizada, excepción que, en la línea de lo que tradicionalmente viene admitiendo la legislación urbanística, posibilita otros usos en suelo no urbanizable distintos a los inherentes a «la naturaleza de los terrenos», por utilizar los mismos términos de que se sirve el artículo 20.1 de la citada Ley 6/1998. En efecto, el párrafo segundo de este artículo 20 dispone que: «Excepcionalmente, a través del procedimiento previsto en la legislación urbanística, podrán autorizarse actuaciones específicas de interés público, previa justificación de que no concurren las circunstancias previstas en el apartado 1 del artículo 9 de la presente Ley».

La lectura de la disposición transcrita, a mi juicio, ofrece una calculada imprecisión llamada a ser integrada por la legislación urbanística - la estatal supletoria (Texto Refundido de 1976) o la legislación urbanística de cada Comunidad Autónoma- - No obstante esa imprecisión, han de advertirse tres prescripciones de interés a nuestros efectos. En primer lugar, la remisión a la normativa urbanística de desarrollo de la propia previsión básica que contiene el artículo 20.1, en su párrafo segundo, en cuanto al procedimiento autorizatorio de actuaciones de interés público en suelo no urbanizable más allá de los que se consideran usos del mismo conforme a la naturaleza de los terrenos, procedimiento al que, con referencia a la normativa urbanística de Castilla y León, aludiremos más adelante. En segundo lugar, la exigencia de un interés público como argumento justificativo de la autorización que habilita para realizar en suelo no urbanizable usos distintos a los relacionados con fines agrícola, forestal, ganadero, cinegético o a algunos otros vinculados al aprovechamiento de los recursos naturales, exigencia genérica con la que el redactor de la Ley 6/1998 sitúa esta autorización en un lugar semejante al que ya la situó el artículo 85.1.2. ${ }^{\mathrm{a}} \mathrm{del}$ Texto Refundido en materia urbanística de $1976^{24}$, sin perjuicio, claro

${ }^{24}$ Es conocido el casuismo con que se ha venido reconociendo la utilidad pública o el interés social de las edificaciones o instalaciones en suelo no urbanizable en aplicación del artículo 86.1 en relación con el artículo 85.1.2. ${ }^{\mathrm{a}}$, ambos del Texto Refundido en materia urbanística de 1976; como simples ejemplos de la, a veces, aleatoriedad con que se han manifestado los Tribunales ante la pretendida autorización por causa de utilidad pública o interés social para realizar usos constructivos o edificatorios en suelo no urbanizable pueden consultarse las recientes Sentencias del Tribunal Supremo, de 14 de abril de 1998 (Ar. 4.395) y de 18 de noviembre de 1998 (Ar. 9.332), en las que judicialmente se contienen posiciones contradictorias acerca de la apreciación de utilidad pública o interés social en la utilización del suelo no urbanizable para realizar actividades extractivas; o las Sentencias, también del Tribunal Supremo, de 5 de marzo de 1997 (Ar. 1.662) y 27 de octubre de 1997 (Ar. 7.634), que mantienen posturas diferentes en cuanto a la apreciación de la utilidad pública o el interés social en la realización de instalaciones en suelo no urbanizable protegido. A mi juicio, como ya señalé en otro lugar, esta aleatoriedad encuentra explicación en la ausencia de planea- 
está, de que el artículo 20.1, párrafo segundo, de la Ley 6/1998 constituya una previsión básica, susceptible de desarrollo autonómico, como comprobaremos más tarde al analizar la legislación urbanística de Castilla y León. Por último, la cláusula que estamos considerando contiene una referencia limitativa de la - ya de por sí excepcional — autorización para realizar actuaciones ajenas a la naturaleza de los terrenos clasificados como suelo no urbanizable, al exigir que la mentada autorización haya de ir precedida de la cumplida justificación de que no concurren las circunstancias previstas en el apartado 1 del artículo 9 de la Ley; pues bien, esta cláusula, a mi juicio, lejos de prohibir la apreciación del interés público en actuaciones a realizar en terrenos clasificados como suelo no urbanizable por concurrir en ellos las condiciones que contempla el artículo $9.1 \mathrm{y}$, consecuentemente, impedir cualquier uso que no sea «conforme con la naturaleza de los terrenos», lo que está impidiendo es que la autorización de usos por haber sido apreciado el interés público de los mismos en terrenos clasificados como suelo no urbanizable, al estar afectados por alguna de las circunstancias que prevé el artículo 9.1, pueda conducir a la transformación de las características del terreno, por tratarse, por tanto, de un uso incompatible con su especial régimen de protección, por los riesgos naturales que aquél pudiera comportar, o por entrar en contradicción con la protección que exige el demanio ${ }^{25}$; igualmente, parece ajustado considerar que ese mismo límite a la autorización ex interés público afecta a los terrenos clasificados como suelo no urbanizable por el planeamiento general (art. 9.2) para preservar alguno de los valores paisajístico, histórico... u otros, lo que supone prohibir la autorización de referencia en cuanto suponga la realización de un uso capaz de producir una transformación en el terreno que ponga en riesgo los valores protegidos.

\section{LOS USOS DEL SUELO RÚSTICO EN CASTILLA Y LEÓN}

El suelo rústico en Castilla y León, una vez en vigor la Ley $5 / 1999$, de 8 de abril, de Urbanismo, está abocado a dejar de ser la clase de suelo de la que las técnicas e instrumentos del Derecho urbanístico prácticamente se desentienden, sino todo lo contrario. En efecto, la citada Ley autonómica contiene un amplio número de previsiones llamadas a disciplinar la utiliza-

miento o en su deficiente comportamiento en suelo no urbanizable, que dificilmente puede ser suplido mediante el recurso a la técnica de los conceptos jurídicos indeterminados, que es a donde nos remiten las expresiones «utilidad pública e interés social», vid. QUINTANA LOPEZ, «Tradición y renovación...», cit., pp. 108 y 109.

${ }^{25}$ En esta línea argumental, vid. las Sentencias del Tribunal Supremo de 7 de julio de 1997 (Ar. 5.924) y de 27 de octubre de 1997 (Ar. 7.634). 
ción e, incluso, las facultades dispositivas sobre el suelo rústico, previsiones que unas veces son comunes a las demás clases de suelo ${ }^{26}$, otras son específicamente aplicables al suelo rústico, a todo el suelo así clasificado o así considerado en los municipios carentes del correspondiente instrumento de planeamiento ${ }^{27}$, pero el grueso de previsiones incidentes sobre esta clase de suelo regulan los usos del mismo partiendo de la básica distinción ya conocida entre usos normales y usos excepcionales.

Los que por contraposición a los excepcionales, denominados aquí normales, son como sabemos los usos agrícola, ganadero, forestal, cinegético u otros análogos vinculados a la utilización de los recursos naturales (artículo 23.1). Los usos excepcionales, más allá de la básica previsión del artículo 20.1 de la Ley 6/1998, del Estado, están expresamente relacionados en el artículo 23.2 de la Ley de Urbanismo de Castilla y León ${ }^{28}$.

Pues bien, teniendo en cuenta esa diversidad de usos excepcionales que pueden efectuarse sobre el suelo rústico, así como las distintas categorías en que pueden dividirlo los correspondientes instrumentos de planeamiento o, en su caso, de ordenación territorial, el legislador de Castilla y León ha previsto expresamente los distintos usos que pueden llegar a realizarse en los diversas categorías de suelo rústico a partir de la triple consideración de usos permitidos ${ }^{29}$, usos sujetos a autorización de la

${ }^{26}$ Los artículos 8 y 9 de la Ley que ahora estamos considerando regulan respectivamente los deberes de uso y conservación y los deberes de adaptación al ambiente, cuyas previsiones son aplicables a las distintas clases de suelo y, también, al clasificado como nústico (artículo 24.1 de la misma Ley).

${ }^{27}$ Bajo el rótulo de «Deberes y limitaciones en suelo rústico», el artículo 24 obliga a los propietarios de esta clase de suelo a realizar o permitir a la Administración la realización de trabajos de defensa del suelo y la vegetación; prohibe las parcelaciones urbanísticas en suelo rústico en los términos que se derivan del número dos del precepto citado; prevé límites al ejercicio del ius edificandi en suelo rústico; y, por último, su número cuatro, textualmente dispone: «En suelo nústico las Administraciones públicas nunca sufragarán ni ejecutarán obras de urbanización, salvo que se deriven de la aplicación de la normativa sectorial o del planeamiento urbanístico", dicción que incluye una cláusula de excepción en favor de las Administraciones públicas para sufragar o ejecutar obras de urbanización en suelo rústico en ausencia o en contradicción con el planeamiento, con apoyo en lo que pueda prever la legislación sectorial, excepción de interpretación necesariamente restrictiva.

${ }^{28}$ Construcciones e instalaciones vinculadas a los usos normales; actividades extractivas así como las construcciones e instalaciones destinadas a dichas actividades; obras públicas e infraestructuras y las construcciones e instalaciones necesarias para su ejecución, conservación y servicio; construcciones e instalaciones propias de asentamientos tradicionales, viviendas unifamiliares que no formen núcleo de población, obras de rehabilitación, reforma y ampliación de construcciones e instalaciones existentes; así como otros usos de interés público.

${ }^{29}$ Se consideran usos permitidos en cada categoría de suelo, sin perjuicio de las restricciones que pueda introducir el planeamiento correspondiente, los compatibles con la protección de cada categoría de suelo rústico, estando sometidos a las autorizaciones que prevean las normativas sectoriales y, en su caso, la correspondiente licencia urbanistica [art. 25.1.a)]. 
Administración autonómica ${ }^{30} \mathrm{y}$ usos prohibidos ${ }^{31}$. De esta forma, el sistema se hace descansar en los instrumentos de planificación habilitados para clasificar los terrenos como suelo rústico $\mathrm{y}$, dentro de él, delimitar algunas o todas las categorías de esta clase de suelo, y sobre los terrenos así delimitados están llamadas a incidir las previsiones que el propio planeamiento contenga, permitiendo, sometiendo a previa autorización autonómica o prohibiendo en cada categoría de suelo rústico los usos correspondientes, determinaciones del planeamiento que, en todo caso, deben respetar lo dispuesto en los artículos 26 a 29 de la Ley 5/1999, de 8 de abril, de Urbanismo de Castilla y León, que contienen unos mínimos de protección de los terrenos de cada categoría de suelo rústico ${ }^{32}$, sin perjuicio de que el planeamiento pueda introducir mayores limitaciones para dotar a los terrenos afectados de un mayor nivel de protección. En todo caso, como fácilmente se advierte de la lectura del artículo 23.1 de esta ley, los usos excepcionales que puedan realizarse por estar permitidos o ser autorizables en las distintas categorías de suelo rústico se suman a los que son conformes con la naturaleza de los terrenos clasificados como suelo rústico (agrícolas, ganaderos, ...), por ser considerados inherentes al mismo expresamente por el legislador (art. 20.1 de la Ley 6/1998, de 13 de abril, sobre Régimen del Suelo y Valoraciones y art. 23.1 de la Ley 5/1999, 8 de abril, de Urbanismo de Castilla y León).

${ }^{30}$ Previamente al otorgamiento de la licencia urbanística municipal, es preciso contar con la autorización expedida por el órgano correspondiente de la Administración autonómica para aquellos usos del suelo rústico en que deba valorarse el interés público que justifique la autorización autonómica [art. 25.1.b)].

${ }^{31}$ Están prohibidos los usos en suelo rústico que sean incompatibles con la protección de los valores de cada categoría de suelo y, en todo caso, impliquen un riesgo relevante de erosión o deterioro ambiental [art. 25.1.c)].

32 Aunque la cita es extensa, resulta necesaria para conocer los mínimos de protección que la Ley de Urbanismo de Castilla y León prevé para las distintas categorias de suelo rústico, previsiones que se corresponden con los artículos 26 a 29 de la citada Ley. En suelo rústico común (art. 26), están permitidas las construcciones e instalaciones vinculadas a explotaciones agrícolas, ganaderas, forestales, cinegéticas y otras análogas, así como las obras públicas e infraestructuras en general y construcciones e instalaciones vinculadas a su ejecución, conservación y servicio; están sujetos a autorización autonómica los demás usos en suelo rústico relacionados en el artículo 23.2 (nota al pie, $n .^{\circ} 28$ ). En suelo rústico de entorno urbano (art. 27), están permitidas las obras públicas e infraestructuras en general, $y$ las construcciones e instalaciones vinculadas a su ejecución, conservación y servicio; están prohibidas las actividades extractivas, los usos industriales, comerciales y de almacenamiento y las construcciones e instalaciones vinculados a ellas, así como las construcciones destinadas a vivienda unifamiliar aislada; están sujetos a autorización el resto de usos excepcionales del suelo rústico (art. 23.2). En suelo rústico de asentamiento tradicional (art. 28), se permitirán los usos caracteristicos y tradicionales del asentamiento y se autorizarán los que guarden relación directa con las necesidades de la población residente, todo ello mediante las determinaciones que contenga el planeamiento. Por último, el suelo rústico con protección (art. 29), en el cual deben distinguirse los terrenos que, incluidos en esta categoría, ya dispusieran de algún régimen de protección conforme a la normativa específica (espacios naturales protegidos, ordenación territo- 


\section{A) Régimen de autorizaciones de usos excepcionales en suelo rústico}

En algunos casos, los llamados usos excepcionales en suelo rústico, previamente a la licencia urbanística, deben ser autorizados ${ }^{33}$ después de ser constatado el interés público del uso solicitado mediante la tramitación del correspondiente procedimiento cuyo hitos están previstos en el artículo 25.2 de la Ley 5/1999, de Castilla y León, tramitación que se prevé integrada en el procedimiento de otorgamiento de licencia urbanística regulado en el artículo 99 de la misma Ley.

Interesa destacar la duplicidad de procedimientos y, consecuentemente, la duplicidad de resoluciones con que finalizan aquéllos, pero, sobre todo, los diferentes aspectos que deben ser objeto de análisis y valoración en ambos. En efecto, así como la licencia urbanística pone fin al procedimiento de contraste de los actos de uso del suelo con la legalidad urbanística que sea aplicable, la autorización que nos ocupa culmina un procedimiento cuyo objetivo es la valoración del interés público presente en la pretendida utilización del suelo rústico cuando, como sabemos, esa presencia se ha considerado inexcusable. Pues bien, a mi juicio, esa valoración, resultado de la que ha de surgir la autorización, con o sin condiciones, o su denegación, debe reflejar la consideración de variadas circunstancias; unas expresamente exigidas por el propio legislador, como la superficie mínima de la parcela y las distancias mínimas con colindantes, o la dotación de servicios que se prevean incorporar al uso solicitado.... y otras que pueda imponer el planeamiento ${ }^{34}$, así como la adecuación a la Ley, al planeamiento y a la legislación sectorial ${ }^{35}$; otras circunstancias concurrentes, sin embargo, aun no citadas por el legislador, también deben integrar el juicio valorativo del interés público que acompañe al uso solicitado, circunstancias entre las que, sin duda, destaca el componente socioeconómico del proyecto. En definitiva, la valoración del interés pú-

rial...), en cuyo caso los usos de que son susceptibles los terrenos sometidos a especifica tutela, será el que se derive de su propia normativa; en el resto de terrenos de categoría «suelo rústico con protección", estarán prohibidas las actividades extractivas, los usos industriales, comerciales y de almacenamiento y las construcciones destinadas a vivienda unifamiliar aislada; por el contrario, estarán sujetos a autorización los demás usos excepcionales que relaciona el artículo 23.2; todo ello, en efecto, susceptible de modulación para otorgar una mayor protección a los terrenos incluidos en esta categoría de suelo rústico, de conformidad con la consideración de mínimos de protección que contienen todas las previsiones señaladas.

33 Vid. nota anterior.

34 Vid. artículo 25.3.a) y b) de la Ley 5/1999, de Urbanismo de Castilla y León.

35 Vid. artículo 25.2.c) de la Ley 5/1999, de Urbanismo de Castilla y León. 
blico no suple ni se impone a ninguna otra de las perspectivas sectoriales, ni tampoco a la urbanística, que se proyectan a través de los correspondientes procedimientos y licencias o autorizaciones, sino que se trata de una valoración distinta, en la que se integran apreciaciones normativamente pautadas y otras más cercanas al campo de la experiencia y de las soluciones técnicas, como componentes del concepto jurídico indeterminado a que reconduce la expresión «interés público».

La competencia resolutoria, es decir, la apreciación o no del interés público del uso cuya autorización se solicita corresponde a la Administración autonómica o al propio municipio en cuyo término municipal se pretende ejecutar el correspondiente proyecto. En efecto, aunque el artículo 25.1.a) de la Ley 5/1999 de Urbanismo, de Castilla y León, sin otras especificaciones, somete los usos excepcionales en suelo rústico a autorización de la Administración autonómica, el propio artículo 25.2.c) desmiente lo anterior, pues, conforme textualmente establece «concluida la información pública, el Ayuntamiento, en los Municipios con población igual o superior a 20.000 habitantes o que cuenten con Plan General de Ordenación Urbana, o la Comisión Territorial de Urbanismo, en los demás Municipios, examinará la adecuación de la solicitud a esta Ley.... y resolverá concediendo la autorización simplemente o con condiciones, o bien denegándola motivadamente». En definitiva, la aprobación del interés público del uso pretendido se retiene por los municipios que alcancen el número de habitantes indicado o que cuenten con el específico instrumento de planeamiento general señalado, lo cual, en la práctica, supone una absorción de este procedimiento por el de otorgamiento de la licencia urbanística, lo que se justifica en las circunstancias que habilitan la apreciación municipal del interés público; es decir, en la existencia de un Plan General de Ordenación Urbana que contenga las determinaciones suficientes en suelo rústico para ilustrar adecuadamente esa apreciación, y en el número de habitantes del municipio, igual o superior a 20.000 , aunque se carezca del Plan General, que normalmente se corresponde con un complejo organizativo municipal capaz de realizar esa valoración. Contrariamente, será la Administración urbanística de tutela, en particular la Comisión Territorial de Urbanismo, la que, sin perjuicio de otras autorizaciones y licencias - significativamente la urbanística- habrá de efectuar la valoración del interés público como trámite preceptivo y no vinculante en relación con la licencia urbanística municipal. 


\section{B) Consideración de los usos del suelo rústico en los municipios sin planeamiento}

Los municipios de referencia son los que no se hallan afectados por alguno de los instrumentos de planeamiento general habilitados para clasificar los terrenos del término municipal o, en su caso, por las Directrices de Ordenación de Ámbito Subregional, en cuanto instrumentos aptos para contener determinaciones de clasificación del suelo, como ya ha quedado indicado en otro lugar. En estos municipios, la consideración de suelo rústico viene determinada residualmente a partir de los terrenos que, por reunir las características que prevé el artículo 30.a) de la Ley de Urbanismo de Castilla y León ${ }^{36}$, deben ser considerados como suelo urbano. En estos municipios sin planeamiento, el suelo rústico, como regla general, tendrá la consideración común, única categoría, por tanto, de esta clase de suelo en municipios carentes de planeamiento; no obstante, esta regla admite la existencia dentro del suelo rústico de las categorías de protección especial previstas en el artículo 16, cuyo contenido ya conocemos, siempre que los terrenos se hallen sometidos a un régimen de especial protección conforme a la específica normativa sectorial ${ }^{37}$.

En los terrenos así considerados como rústicos y, en su caso, en función de la categoría en que quepa su inclusión, se podrán llevar a cabo los usos normales y excepcionales, en los mismos términos que en los municipios en que los terrenos hayan sido clasificados por el correspondiente instrumento de planeamiento. La falta de éste y la eventual ausencia de las distintas categorías previstas como posibles en el suelo rústico, sin duda contribuye a que la valoración del interés público en el marco del procedimiento autorizatorio de usos excepcionales en suelo rústico - común, en el supuesto ahora considerado-, se halle alguna de las correspondientes determinaciones urbanísticas inherentes al planeamiento que pauten los usos excepcionales en suelo rústico y, por tanto, las decisiones resolutorias, municipales o autonómicas en función del número de habitantes del municipio, que pongan fin al procedimiento de autorización; es

\footnotetext{
36 Terrenos que formen parte de un núcleo de población y cuenten con acceso rodado, abastecimiento de agua, saneamiento y suministro de energía eléctrica, asi como los terrenos consolidados por la edificación en al menos la mitad de los espacios no ocupados por vías públicas o espacios libres existentes.

37 Artículo 32.1 de la Ley de Urbanismo de Castilla y León; en particular, en este mismo precepto se otorga ope legis la categoría de suelo rústico con protección cultural a «los terrenos situados en el entorno de protección de inmuebles declarados como Bien de Interés Cultural o en su defecto dentro de una banda de 50 metros desde su limite exterion?.
} 
por ello que, como importante cautela, el artículo 32.2 de la Ley de Urbanismo de Castilla y León ha previsto unas limitaciones a los usos del suelo rústico en municipios sin planeamiento ${ }^{38}$, que abundan en las tradicionales normas de directa aplicación previstas en los artículos 73 y 74 del Texto Refundido en materia urbanística de 1976.

38 «Los propietarios tendrán los derechos, deberes y limitaciones previstos en el capítulo anterior, y deberán respetar además las siguientes normas: a) La altura máxima será de dos plantas, salvo para las construcciones e instalaciones que justifiquen la necesidad técnica de superarla. b) Se exigirá la adaptación a las caracteristicas del entorno inmediato y del paisaje circundante, en cuanto situación, uso, altura, volumen, color, composición, materiales y demás características, así como el respeto de la vegetación y de los perfiles naturales del terreno». 
